\title{
Assembly of a New Keggin-Templated Supramolecular Compound by Silver Salt and 4, 4'-dipyridine-N, N'-dioxide
}

\section{Ligand}

Zhuanfang Zhang ${ }^{a, b}$, Huiyuan Ma ${ }^{a}{ }^{*}$, Haijun Pang ${ }^{a}$, Chunjing Zhang ${ }^{a, c_{*} *}$ Tingting $\mathrm{Yu}^{a}$, Shaobin $\mathrm{Li}^{a}$ and Chunyan $\mathrm{Zhao}^{a}$

${ }^{a}$ Key Laboratory of Green Chemical Engineering and Technology of College of Heilongjiang Province, College of Chemical and Environmental Engineering, Harbin University of Science and Technology, Harbin 150040, P. R. China

${ }^{b}$ College of Chemistry and Chemical Engineering, Qiqihar University, Qiqihar 161006, P. R. China,

${ }^{c}$ College of Pharmaceutical Sciences, Heilongjiang University of Chinese Medicine, Harbin 150040, P. R. China

*Correspondence to: H.Y. Ma, Tel./fax: 86-0451-86392716;

**Correspondence to: C.J. Zhang, Tel./fax.: 86-451-86688575;

E-mail addresses: mahy017@163.com, zhangcj922@163.com. 


\begin{abstract}
A

new polyoxometalate

(POM)-templated

compound,

$\mathrm{Ag}_{3}(\mathrm{dpdo})_{7}\left(\mathrm{H}_{2} \mathrm{O}\right)_{2} \mathrm{H}_{3} \subset\left[\mathrm{PW}_{12} \mathrm{O}_{40}\right]_{2}$ (dpdo $=4,4$-dipyridine- $\mathrm{N}, \quad \mathrm{N}$-dioxide $)$ was hydrothermally synthesized, and characterized by elemental analyses, IR spectroscopy, and single X-ray diffraction. Compound 1 crystallizes in the triclinic space group $P-1$, and the basic structure unit of $\mathbf{1}$ is constructed by $\left[\mathrm{PW}_{12} \mathrm{O}_{40}\right]^{3-} \mathrm{PW}_{12}$ clusters, $\mathrm{Ag}^{+}$ cations, and dpdo molecules. In 1, the dpdo ligand acts as a bi-dentate linkage coordinating with two $\mathrm{Ag}^{+}$ions through terminal oxygen atoms to form a two-dimensional (2D) bi-layer, and the neighboring 2D layers are stagger-peaked with each other to form a 3D open framework with the rhombus-like apertures. The $\mathrm{PW}_{12}$ anions as templates are encapsulated into the channels and arranged in an A-B-A-B staggered manner. Additionally, the electrochemical studies show that $\mathbf{1}$ has a good electrocatalytic activity towards reduction of hydrogen peroxide $\left(\mathrm{H}_{2} \mathrm{O}_{2}\right)$ and iodated $\left(\mathrm{IO}_{3}{ }^{-}\right)$and the catalytic efficiency (CAT) of compound $\mathbf{1}$ toward the reduction of $\mathrm{H}_{2} \mathrm{O}_{2}$ and $\mathrm{IO}_{3}{ }^{-}$is $c a .116 .7 \%$ and $40.9 \%$, respectively. The results exhibit that $\mathbf{1}$ could be used as electrocatalyst in the electrical reduction of $\mathrm{H}_{2} \mathrm{O}_{2}$.
\end{abstract}

Keywords: Keggin; polyoxometalate template; electrocatalytic properties

In recent years, assembly of the supramolecular structures has captivated the attention of many investigators due to their intriguing molecular structure as well as their potential applications [1-7]. An effective synthesis strategy for constructing novel supramolecular compounds is the utilization of templates, which can direct the supramolecular array of building blocks with contrary charges. Polyoxometalates (POMs) are one of perfect anionic templates and charge-compensating guests to stabilize the construction of supramolecular host frameworks owing to their diversity structures, controllable shapes, sizes, high negative charges [8]. Furthermore, the POMs are endowed with particular multifuctionalities, such as, catalytic activity and reversible redox behavior [9, 10]. Thus, incorporating POM into host frameworks may create new opportunities to utilize the redox properties of the POMs and carry out redox reactions within the intercrystalline voids of the supramolecular framework [11-14]. Hereto, remarkable progress about POM-templated supramolecular hybrid 
materials have been made based on such a self-assembly reaction [15]. During the assembly process, the matching between open host metal-organic framework and guest POMs molecules is critical for synthetic POM-templated supramolecular hybrid materials. The linear ligand is an appropriate synthon for constructing open host framework. The N-donor ligand especially 4, 4'-bipyridine has been extensively used as linker to construct metal-organic frameworks. In 1999, Zubieta and co-worker published a excellent review that summarized a series of metal-organic frameworks by using 4, 4'-bipyridine as bridging ligand [16], and these frameworks can been as host molecules to encapsulate some small anions (such as $\mathrm{Cl}^{-}, \mathrm{Br}^{-}, \mathrm{NO}_{3}^{-}, \mathrm{BF}_{4}^{-}, \mathrm{PF}_{6}^{-}$, $\left.\left[\mathrm{Mo}_{8} \mathrm{O}_{26}\right]^{4-}\right)$ to form inorganic-organic entities [17-21]. However, the size of the Keggin type POMs is the nano-metric, which is obviously large in contrast to the above-mentioned small anions. Consequently, the host frameworks that constructed by 4, 4'-bipyridine ligand is difficulty to encapsulate Keggin type POMs anions [22]. In order to satisfy the afore-mentioned requirements for POM-templated assembly, the selection of appropriate rigid linear ligand is very important. The 4, 4'-bipyridine-N, N'-dioxide (dpdo) ligand as a derivative of the 4, 4'-bipyridine possesses longer spacer ligand for construction the metal-organic host framework with higher capacity [23-26], and potential coordination sites for hydrogen bonding toward oxygen atoms of POMs and water molecules forming $\mathrm{O}-\mathrm{H} \cdots \mathrm{O}$ interactions $[27,28]$. A series of prominent preliminary work about dpdo ligand as bridging ligand for the construction of Keggin-templated supramolecular compounds have been reported by Duan et al. [29-33]. Subsequently, in 2013, our group reported $\mathrm{Ce}^{3+} / \mathrm{Nd}^{3+}$-dpdo-Keggin complexes and a $3 \mathrm{~d}-4 \mathrm{f}$ heterometallic 3D POM-based hybrid constructed by the dpdo ligands $[34,35]$. However, the metal ions in these metal-dpdo host frameworks were generally restricted to lanthanide cations [29, 30, 32, 34-36], except for the several examples [31,32] (please see Table S1, the summarization of POM-based hybrid compounds constructed by dpdo ligand). As is well known, $\mathrm{Ag}^{+}$is widely applied in luminescent, antibacterial and catalytic materials [37-39]. Further, $\mathrm{Ag}^{+}$possesses flexible coordination modes and high affinity to $\mathrm{O}$ donors, which may easily form covalent links between $\mathrm{Ag}^{+}$and POMs/ligands [40]. Nevertheless, the use of $\mathrm{Ag}^{+}$as metal ion to coordination with dpdo ligand for construction of novel Keggin-templated supramolecular compounds has not been fully realized so far.

Taking this into account, by choosing $\mathrm{H}_{3}\left[\mathrm{PW}_{12} \mathrm{O}_{40}\right] \cdot 12 \mathrm{H}_{2} \mathrm{O}$, dpdo ligand, and 
$\mathrm{AgNO}_{3} \cdot \mathrm{H}_{2} \mathrm{O}$ salt, fortunately a new supromolecular compound, $\mathrm{Ag}_{3}(\mathrm{dpdo})_{7}\left(\mathrm{H}_{2} \mathrm{O}\right)_{2} \mathrm{H}_{3} \subset\left[\mathrm{PW}_{12} \mathrm{O}_{40}\right]_{2}$ (1) has been isolated via using hydrothermal method. Compound 1 show 3D open framework with the rhombus-like apertures, in which the $\left[\mathrm{PW}_{12} \mathrm{O}_{40}\right]^{3-}\left(\mathrm{PW}_{12}\right)$ templates are encapsulated into the channel and arranged in an A-B-A-B staggered manner. The electrochemical studies show that $\mathbf{1}$ has a good electrocatalytic activity towards reduction of both hydrogen peroxide $\left(\mathrm{H}_{2} \mathrm{O}_{2}\right)$ and iodated $\left(\mathrm{IO}_{3}{ }^{-}\right)$. Additional, 1-CPE possesses better electrocatalytic effect in the reduction of $\mathrm{H}_{2} \mathrm{O}_{2}$.

Compound 1 was prepared under hydrothermal conditions with a mixture of $\mathrm{H}_{3}\left[\mathrm{PW}_{12} \mathrm{O}_{40}\right] \cdot 12 \mathrm{H}_{2} \mathrm{O}(300 \mathrm{mg}, 0.1 \mathrm{mmol}), \mathrm{AgNO}_{3} \cdot \mathrm{H}_{2} \mathrm{O}$ (80mg, 0.4mmol), dpdo (90 $\mathrm{mg}, 0.5 \mathrm{mmol})$, and $\mathrm{H}_{2} \mathrm{O}(10 \mathrm{~mL})(\mathrm{pH}=1.5)$ at $170{ }^{\circ} \mathrm{C}$ for 3 days [41]. And 1 crystallizes in triclinic space group $P-1$ [42].

The bond valence sum (BVS) calculations [43] show that all $\mathrm{W}$ and $\mathrm{Ag}$ atoms of compound $\mathbf{1}$ are in the + VI and + I oxidation state, respectively. Since $\mathbf{1}$ was isolated from acidic aqueous solution, the oxygen atoms of POM anions could be protonated in acidic aqueous solution [44, 45]. Three protons were attached to POMs to compensate for charge balance, then $\mathbf{1}$ is formulated as $\mathrm{Ag}_{3}(\mathrm{dpdo})_{7}\left(\mathrm{H}_{2} \mathrm{O}\right)_{2} \mathrm{H}_{3} \subset\left[\mathrm{PW}_{12} \mathrm{O}_{40}\right]_{2}$. In compound 1, there are two crystallographically unique $\mathrm{Ag}^{\mathrm{I}}$ ions (Ag1 and $\left.\mathrm{Ag} 2\right)$, which exhibit distinct coordinated modes. $\mathrm{Ag} 1$ ion adopts a five-coordinated mode in a distorted trigonal bipyramidal geometry achieved by four $\mathrm{O}$ atoms from four dpdo ligands and one $\mathrm{O}$ atom from a water molecule. The $\mathrm{Ag} 2$ cation is hexa-coordinated mode in a near-octahedral geometry formed by four $\mathrm{O}$ atoms from four dpdo ligands, and two $\mathrm{O}$ atoms from two water molecules. The dpdo ligand acts as a bi-dentate linkage coordinating with two $\mathrm{Ag}^{+}$ions through terminal oxygen atoms. Consequently, a two-dimensional (2D) bi-layer sheet was formed by the dpdo ligands and silver ions (Fig. 1). From the topological view, when Ag1, Ag2 ions are viewed as three, six connecting nodes, respectively, a $(3,6)$-connected topology is generated (Fig. S1). These neighboring identical 2D networks are stagger-peaked with each other to form an open 3D framework with large rhombus-like apertures in a given direction (Fig. S2), The $\mathrm{PW}_{12}$ anion as a "guest" 
cluster anion was encapsulated into the open channel structure and well surrounded by these "host" rhombus-like units (Fig. 2). And this kind of packing arrangement may decrease the molecular repulsion with contrary charges and stabilizing the whole crystal structure $[8]$.

\section{[Insert Fig. 1]}

[Insert Fig. 2]

The size of the rhombus-like units of the open framework is $c a .12 .29 \times 12.23 \AA$, which is enough large to accommodate nanoscale Keggin POM anion. In each tunnel, the $\mathrm{PW}_{12}$ templates are arranged in staggered manner in an A-B-A-B model (see Fig. 3), furthermore, top view of the part channel shows that the $\mathrm{PW}_{12}$ anions adopt stagger-peaked with approximate intersection angle of $30^{\circ}$ (illustrated in Fig. 3b). As is known, most of the already known structures feature of the fashion that the POM anions act as templates existing in the channels along one direction. However, this work represents the first 3D supramolecular structure with noncoordinating POM anions act as templates in different angles.

\section{[Insert Fig. 3]}

The IR spectra of compounds $\mathbf{1}$ is shown in Figure S3. Characteristic peaks at 1013.8, 966.2, 934 and $772.2 \mathrm{~cm}^{-1}$ for $\mathbf{1}$, are attributed to $v(\mathrm{P}-\mathrm{O}), v(\mathrm{~W}=\mathrm{O})$, and $v$ (W-O-W) [46-49], respectively. The bands at 1622.6, 1503, 1387, $1345 \mathrm{~cm}^{-1}$ in IR spectra could be regarded as the characteristic peaks of the dpdo ligand [50].

The XRD pattern for compounds 1 was presented in Figure S4. The diffraction peaks of both simulated and experimental patterns match in the key positions. The difference in reflection intensities between the simulated and the experimental patterns may be due to the different orientation of the crystals in the sample $[45,51]$. In addition, the diffraction peaks of both simulated and experimental patterns do not match well in some positions, which may be just ascribed to that the sample has been deposited for long time and might be partly pulverized. Thus, the phase purity of the $\mathbf{1}$ is basically good.

The Keggin-type POMs are known to exhibit well defined redox waves and are usually considered to be electron reservoirs [52]. One of their domains of application 
thus concerns electro catalysis [53]. In order to study the electrochemical behavior of 1, the compound was used as solid modifier to fabricate three-dimensional bulk-modified carbon paste electrode (CPE) by direct mixing method due to its insolubility. The CPE was prepared according to the previous method [54]. The cyclic voltammetric behavior for 1-CPE in $0.2 \mathrm{M} \mathrm{Na}_{2} \mathrm{SO}_{4} / \mathrm{H}_{2} \mathrm{SO}_{4}$ buffer solution $(\mathrm{pH}=4.5)$ was recorded in the potential range of -1.0 to $0.8 \mathrm{~V}$, as shown in Fig. S5. There exist two pairs of reversible redox peaks with half-ware potentials $E_{1 / 2}$ at -0.31 (III-III') and $-0.19 \mathrm{~V}$ (II-II'), which can be ascribed to redox process of tungstate in 1 [55]. In addition, there is one irreversible anodic peak (I) at $+0.22 \mathrm{~V}$, which is assigned to the oxidation of $\mathrm{Ag}^{+}[56-59]$. When the scan rates varied from 40 to $240 \mathrm{mV} \cdot \mathrm{s}^{-1}$, the peak potentials change gradually: the cathodic peak potentials shift toward the negative direction and the corresponding anodic peak potentials to the positive direction with increasing scan rates. Furthermore, up to $240 \mathrm{mV} \mathrm{s}^{-1}$ the peak currents are proportional to the scan rate, which indicates that the redox processes are surface-controlled, and the exchanging rate of electrons is fast [60] ( Fig. S6).

The electrocatalytic properties of 1-CPE have also been investigated towards the reduction of hydrogen peroxide $\left(\mathrm{H}_{2} \mathrm{O}_{2}\right)$ and iodated $\left(\mathrm{IO}_{3}{ }^{-}\right)$in $0.2 \mathrm{M} \mathrm{Na}_{2} \mathrm{SO}_{4} / \mathrm{H}_{2} \mathrm{SO}_{4}$ solution (scan rate: $80 \mathrm{mV} \cdot \mathrm{s}^{-1}$ ). With addition of $\mathrm{H}_{2} \mathrm{O}_{2}$ and $\mathrm{IO}_{3}^{-}$, the reduction peak currents for II and III increase gradually while the corresponding oxidation peak currents decrease. The nearly equal current steps for each addition of $\mathrm{H}_{2} \mathrm{O}_{2}$ and $\mathrm{IO}_{3}{ }^{-}$ demonstrate stable and efficient electrocatalytic activity of 1-CPE (see the insert figures of Fig. 4a, b). Furthermore, to compare the electrocatalytic activity of 1-CPE for reduction of $\mathrm{H}_{2} \mathrm{O}_{2}$ and $\mathrm{IO}_{3}{ }^{-}$, the catalytic efficiency (CAT) of 1-CPE can be roughly calculated by using CAT formula [61]. From the chart of the CAT, the CAT values toward the reduction of $\mathrm{H}_{2} \mathrm{O}_{2}$ and $\mathrm{IO}_{3}{ }^{-}$are $c a .116 .7 \%$ and $40.9 \%$, respectively, when the concentrations of $\mathrm{H}_{2} \mathrm{O}_{2}$ and $\mathrm{IO}_{3}{ }^{-}$are $4 \mathrm{mM}$ (Fig. 5). The results show 1-CPE has obvious electrocatalytic effect in the reduction of $\mathrm{H}_{2} \mathrm{O}_{2}$, which suggest that compound 1 could be used as potential electrocatalyst in the electrical reduction of $\mathrm{H}_{2} \mathrm{O}_{2}$.

[Insert Fig. 4] 


\section{[Insert Fig. 5]}

In summary, by choosing dpdo ligand that is a derivative of the 4, 4'-bipyridine, $\mathrm{Ag}^{+}$cation and $\mathrm{PW}_{12}$ Keggin polyanion, a new compound has been synthesized from the hydrothermal reaction. The compound shows an intriguing $3 \mathrm{D}$ open supramolecular framework encapsulated by $\mathrm{PW}_{12}$ templates, which represents the first example of POM-based hybrid constructed by dpdo ligand and $\mathrm{Ag}^{+}$cation. Also, the compound possesses good electrocatalytic activities towards reduction of both $\mathrm{H}_{2} \mathrm{O}_{2}$ and $\mathrm{IO}_{3}{ }^{-}$. To some extend, this work further confirmed that the dpdo molecule with longer spacer ligand than 4, 4'-bipyridine molecule is a suitable synthon, reacting with $\mathrm{Ag}^{+}$cation or generally lanthanide cations, for construction the metal-organic host framework with higher capacity.

\section{Acknowledgments}

This work was financially supported by the NSF of China (21371041, 51572063 and 21501053), the science and technology innovation foundation of Harbin (2014RFXXJ076).

\section{Appendix A. Supplementary material}

Supplementary data associated with this article can be found in the online version.

\section{References}

[1] T.K. Holman, Molecule-constructed microporous materials: long under our noses, increasingly on our tongues, and now in our bellies, Angew. Chem. Int. Ed. 50 (2011) 1228-1230.

[2] B. Nahum, I. Narasimhulu, K.V. Weiner, L.R. Neumann, Phenanthroline-polyoxometalate hybrid compounds and the observation of intramolecular charge transfer, Inorg. Chem. 44 (2005) 4900-4902.

[3] V. Shivaiah, S.K. Das, Inclusion of a $\mathrm{Cu}^{2+}$ ion by a large-cavity crown ether dibenzo-24-crown-8 through supramolecular interactions, Inorg. Chem. 44 (2005) 7313-315.

[4] D.L. Long, Y.F. Song, E.F. Wilson, P. Kgerler, S.X. Guo, A.M. Bond, J.S.J. Hargreaves, L. Cronin, Capture of periodate in a $\left\{\mathrm{W}_{18} \mathrm{O}_{54}\right\}$ cluster cage yielding a catalytically active polyoxometalate $\left[\mathrm{H}_{3} \mathrm{~W}_{18} \mathrm{O}_{56}\left(\mathrm{IO}_{6}\right)\right]^{6-}$ embedded with 
high-valent iodine, Angew. Chem. Int. Ed. 47 (2008) 4384-4387.

[5] W.H. Fang, L. Cheng, L. Huang, G.Y. Yang, A series of lanthanide-based cluster organic frameworks made of heptanuclear trigonal-prismatic cluster units, Inorg. Chem. 52 (2013) 6-8.

[6] Y.R. Qiao, P.F. Hao, Y.L.Fu, Symmetrically related construction and optical properties of two noncentrosymmetric 3D iodides of $\mathrm{d}_{10}$ cation $\left(\mathrm{Cu}^{+}, \mathrm{Ag}^{+}\right)$based on the N-benzylpyridinium and its supramolecular interactions, Inorg. Chem. 54 (2015) 8705-8710.

[7] Y.Y. An, L. Wang, Y. Hu, T.Q. Xu, Y.J. Hou, Spontaneous resolution of evans-showell-type polyoxometalates in constructing chiral inorganic-organic hybrid architectures, Inorg. Chem. 55 (2016) 144-153.

[8] X.L. Wang, C. Xu, H.Y. Lin, G.C. Liu, S. Yang, Q. Gao, A.X. Tian, Tuning the architectures of polyoxometalate-templated complexes by changing the spacer lengths of bis-pyridyl-bis-amide ligands (L): from 1D chains to 2D networks based on different $(\mathrm{CuL})_{\mathrm{n}}$ loops, CrystEngComm. 14 (2012) 5836-5844.

[9] H.N. Miras, M. Sorus, J. Hawkett, D.O. Sells, E.J.L. Mcinnes, Oscillatory template exchange in polyoxometalate capsules: A ligand-triggered, redox-powered, chemically damped oscillation, J. Am. Chem. Soc. 134 (2012) 6980-6983.

[10] Z.Y. Zhang, Q.P. Lin, D. Kurunthn, T. Wu, F. Zuo, S.T. Zheng, C.J. Bardeen, X.H. $\mathrm{Bu}$, P.Y. Feng, Synthesis and photocatalytic properties of a new heteropolyoxoniobate compound: $\mathrm{K}_{10}\left[\mathrm{Nb}_{2} \mathrm{O}_{2}\left(\mathrm{H}_{2} \mathrm{O}\right)_{2}\right]\left[\mathrm{SiNb}_{12} \mathrm{O}_{40}\right] \cdot 12 \mathrm{H}_{2} \mathrm{O}$, J. Am. Chem. Soc. 133 (2011) 6934-6937.

[11] P.C. Yin, D. Li, T.B. Liu, Solution behaviors and self-assembly of polyoxometalates as models of macroions and amphiphilic polyoxometalate-organic hybrids as novel surfactants, Chem. Soc. Rev. 41 (2012) $7368-7383$.

[12] H.N. Miras, J. Yan, D.L. Long, L. Cronin, Engineering polyoxometalates with emergent properties, Chem. Soc. Rev. 41 (2012) 7403-7430.

[13] P.P. Zhang, J. Peng, J.Q. Sha, A.X. Tian, H.J. Pang, Y. Chen, M. Zhu, Assembly of 
two new polyoxometalate-templated supramolecular compounds by utilizing a ligand with a combination of rigidness and flexibility, CrystEngComm. 11 (2009) 902-908.

[14] J. Guo, J. Yang, Y.Y. Liu, J.F. Ma, Two new polyoxometalate-templated supramolecular compounds constructed by a new tridentate ligand 2, 4, 6-tris[1-(4-oxidroxypyridinium)-ylmethyl]-mesitylene, Inorg. Chim. Acta 400 (2013) 51-58.

[15] Q.G. Zhai, X.Y. Wu, S.M. Chen, Z.G. Zhao, C.Z. Lu, Construction of Ag/1, 2, 4-triazole/polyoxometalates hybrid family varying from diverse supramolecular assemblies to 3-D rod-packing framework, Inorg. Chem. 46 (2007) 5046-5058.

[16] P.J. Hagram, D. Hagram, J. Zubieta, Organic-Inorganic Hybrid Materials: From simple-coordination polymers to organodiamine-templated molybdenum oxides, Angrew Chem. Int. Ed. 38 (1999) 2638-2684.

[17] M. Fujito, Y.J. Kwon, S. Wshizu, K. Qgura, Preparation clathroation ability, and catalysis of a two-dimensional square network material composed of cadmium(II) and 4,4'-bipyridine, J. Am. Chem. Soc. 116 (1994) 1151-1152.

[18] Y.H. Wang, L.Y. Feng, Y.G. Li, C.W. Hu, E.B. Wang, N.H. Hu, Novel hydrogen-bonded three-dimensional networks encapsulating one-dimensional covalent chains: $\left[\mathrm{M}(4, \quad\right.$ 4'-bipy $\left.)\left(\mathrm{H}_{2} \mathrm{O}\right)_{4}\right](4$-abs $) 2 \cdot \mathrm{nH}_{2} \mathrm{O} \quad(4, \quad$ 4'-bipy $=4$, 4'-bipyridine; 4-abs = 4-aminobenzenesulfonate) $(\mathrm{M}=\mathrm{Co}, \mathrm{n}=1 ; \mathrm{M}=\mathrm{Mn}, \mathrm{n}=$ 2), Inorg. Chem. 41 (2002) 6351-6357.

[19] M. Fujilta, M. Tominaga, A. Hori, B. Therrien, Coordination assemblies from a Pd(II)-cornered square complex, Acc. Chem. Res. 38 (2005) 371-380.

[20] S.S. Li, H.J. Yan, L.J. Wan, H.B. yang, B.H. Northrop, P.J. Stang, Control of supramolecular rectangle self-assembly with a molecular template, J. Am. Chem. Soc. 129 (2007) 9268-9269.

[21] P.J. Zapf, R.C. Haushalter, J. Zubieta, Crystal engineering of inorganic/organic composite solids: the structure-directing role of aromatic ammonium cations in the synthesis of the 'step'-layered molybdenum oxide phase [4, 4'- $\mathrm{H}_{2}$ bpy] $\left[\mathrm{Mo}_{7} \mathrm{O}_{22}\right] \cdot \mathrm{H}_{2} \mathrm{O}$, Chem. Commun. (1997) 321-322. 
[22] X.Y. Zhao, D.D. Liang, S.X. Liu, C.Y. Sun, R.G. Cao, C.Y. Gao, Y.H. Ren, Z.M. $\mathrm{Su}$, Two dawson-templated three-dimensional metal-organic frameworks based on oxalate-bridged binuclear Cobalt(II)/Nickel(II) SBUs and bpy linkers, Inorg. Chem. 47 (2008) 7133-7138.

[23] B.Q. Ma, S. Gao, H.L. Sun, G.X. Xu, Hydrogen bonding-directed supramolecular structural motifs based on 4,4'-bipyridine dioxide, CrystEngComm. 35 (2001) $1-5$.

[24] D.L. Long, A.J. Blake, N.R. Champness, C. Wilson, M. Schröder, Constructing terbium co-ordination polymers of $4,4^{\prime}$-bipyridine- $\mathrm{N}, \mathrm{N}^{\prime}$-dioxide by means of diffusion solvent mixtures, Chem. Eur. J. 8 (2002) 2026-2033.

[25] B.Q. Ma, S. Gao, H.L. Sun, G.X. Xu, Novel three-dimensional networks cross-linked by two sets of hydrogen bonded frameworks based on 1-D $\left\{\left[\mathrm{M}\left(\mathrm{H}_{2} \mathrm{O}\right)_{4}\left(4,4^{\prime} \text {-dpdo }\right)\right]\left[\mathrm{ClO}_{4}\right]_{2} \cdot 2\left(4,4^{\prime} \text {-dpdo }\right)\right\}_{\mathrm{n}}\left(4,4^{\prime}\right.$-dpdo $=4,4^{\prime}$-bipyridine dioxide; $\mathrm{M}=\mathrm{Co}, \mathrm{Ni}, \mathrm{Cu}$ or Zn), J. Chem. Soc., Dalton Trans. 2001 130-133.

[26] R.J. Hill, D.L. Long, N.R. Champness, P. Hubbersity, M. Schroder, New approaches to the analysis of high connectivity material: design framework based upon $4^{4}$ and $6^{3}$ - subnet tectons, Acc. Chem. Res. 38 (2005) 337-350.

[27] Z.Y. Shi, X.J. Gu, J. Peng, E.B. Wang, Target synthesis of a new bicapped keggin polyoxometalate derivative: $\left[\mathrm{Co}(\mathrm{phen})_{3}\right]_{2}\left[\mathrm{SiMo}_{8}{ }_{8} \mathrm{Mo}_{4}{ }_{4} \mathrm{~V}^{\mathrm{IV}}{ }_{2} \mathrm{O}_{42}\right] \cdot \mathrm{H}_{2} \mathrm{O}$, J. Mol. Struct. 737 (2005) 147-151.

[28] G.L. Guo, Y.Q. Xu, B.K. Chen, Z.G. Lin, C.W. Hu, Two novel polyoxotantalates formed by lindqvist-type hexatantalate and copper-amine complexes, Inorg. Chem. Commun. 14 (2011) 1448-1451.

[29] D.B. Dang, Y. Bai, C. He, J. Wang, C.Y. Duan, Structural and catalytic performance of a polyoxometalate-based metal-organic framework having a lanthanide nanocage as a secondary building block, Inorg. Chem. 49 (2010) $1280-1282$.

[30] M.L. Wei, C. He, Q.Z. Sun, Q.J. Meng, C.Y. Duan, Zeolite ionic crystals assembled through direct incorporation of polyoxometalate clusters with in $3 \mathrm{D}$ metal-organic frameworks, Inorg. Chem. 46 (2007) 5957-5966.

[31] C.Y. Duan, M.L. Wei, D. Guo, C. He, Q.J. Meng, Crystal structures and 
properties of large protonated water clusters encapsulated by metal-organic frameworks, J. Am. Chem. Soc. 132 (2010) 3321-3330.

[32] Q.X. Han, L.J. Zhang, C. He, J.Y. Niu, C.Y. Duan, Metal-organic frameworks with phosphotungstate incorporated for hydrolytic cleavage of a DNA-model phosphodiester, Inorg. Chem. 51 (2012) 5118-5127.

[33] M.L. Wei, C. He, W.J. Hua, C.Y. Duan, S.H. Li, Q.J. Meng, A large protonated water cluster $\mathrm{H}^{+}\left(\mathrm{H}_{2} \mathrm{O}\right)_{27}$ in a 3D metal-organic framework, J. Am. Chem. Soc. 128 (2006) 13318-13319.

[34] T.T. Yu, H.Y. Ma, S.B. Li, H. Liu, H.J. Pang, Interdigitated architectures assembled from $\alpha$-metatungstates and lanthanide-organic complexes, Inorg. Chem.Commu. 33 (2013) 43-47.

[35] T.T. Yu, H.Y. Ma, C.J. Zhang, H.J. Pang, S.B. Li, H. Liu, A 3d-4f heterometallic 3D POMOF based on lacunary Dawson polyoxometalates, Dalton Trans. 42 (2013) 16328-16333.

[36] D.L. Long, A.J. Blake, N.R. Champness, C.Wilson, M. Schroder, Lanthanum coordination networks based on unusual five-connected topologies, J. Am. Chem. Soc. 123 (2001) 3401-3402.

[37] Y. Morishima, D.J. Yound, K. Fujisawu, Structure and photoluminescence of silver(I) trinuclear halopyrazolato complexes, Dalton Trans. 43 (2014) $15915-15928$.

[38] X. Liu, G.C. Guo, M.L. Fu, X.H. Liu, M.S. Wang, J.S. Huang, Three novel silver complexes with ligand-unsupported argentophilic interactions and their luminescent properties, Inorg. Chem. 45 (2006) 3679-3685.

[39] Z.H. Chen, F. Bing, Q. Liu, Z.Q. Zhang, X.M. Fang, Novel Z-scheme visible-light-driven $\mathrm{Ag}_{3} \mathrm{PO}_{4} / \mathrm{Ag} / \mathrm{SiC}$ photocatalysts with enhanced photocatalytic activity, J. Mater. Chem. A3 (2015) 4652-4658.

[40] P.P. Zhang, J. Peng, H.J. Pang, J.Q. Sha, M. Zhu, D.D. Wang, M.G. Liu, The factors affecting on the assembly of $\mathrm{Ag}-\mathrm{H}_{2}$ biim system: size, charge or shape of polyanions, CrystEngComm. 13 (2011) 3832-3841.

[41] A mixture of $\mathrm{H}_{3}\left[\mathrm{PW}_{12} \mathrm{O}_{40}\right] \cdot 12 \mathrm{H}_{2} \mathrm{O}(300 \mathrm{mg}, 0.1 \mathrm{mmol}), \mathrm{AgNO}_{3} \cdot \mathrm{H}_{2} \mathrm{O}(80 \mathrm{mg}$, 0.4mmol), dpdo (90 mg, $0.5 \mathrm{mmol})$, and $\mathrm{H}_{2} \mathrm{O}(10 \mathrm{~mL})$ was stirred for $1 \mathrm{~h}$. The 
$\mathrm{pH}$ was adjusted to 1.5 with $1 \mathrm{M} \mathrm{HNO}_{3}$, then the mixture was transferred to an $18 \mathrm{~mL}$ Teflon-lined reactor and kept under autogenous pressure at $170{ }^{\circ} \mathrm{C}$ for 3 days. The reactor was slowly cooled to room temperature over a period of $10{ }^{\circ} \mathrm{C} / \mathrm{h}$. Brown like block crystals of $\mathbf{1}$ were filtered, washed with water, and dried at room temperature. Yield: $40 \%$ based on $\mathrm{Ag}$. $\mathrm{C}_{70} \mathrm{H}_{63} \mathrm{Ag}_{3} \mathrm{~N}_{14} \mathrm{O}_{96} \mathrm{P}_{2} \mathrm{~W}_{24}$ (7434): Calcd: C, 11.31; H, 0.85; N, 2.64; Ag, 4.35; P, 0.83; W, $59.35 \%$; Found: C, 11.35; H, 0.92; N, 2.60; Ag, 4.28; P, 0.85; W, $59.18 \%$.

[42] Crystal data for $\mathrm{Ag}_{3}(\mathrm{dpdo})_{7}\left(\mathrm{H}_{2} \mathrm{O}\right)_{2} \mathrm{H}_{3} \subset\left[\mathrm{PW}_{12} \mathrm{O}_{40}\right]_{2}: \mathrm{Mr}=7434$, triclinic, space group $P-1, \mathrm{a}=12.297(5) \AA, \mathrm{b}=15.990(5), \AA, \mathrm{c}=16.616(5) \AA, \mathrm{V}=$ 3206.3(19) $\AA^{3}, \mathrm{Z}=1, \mathrm{Dc}=3.847 \mathrm{Mg} / \mathrm{m}^{3}, \mathrm{~F}(000)=3289.0, \mathrm{~T}=293(2) \mathrm{K}$, Rint $=$ 0.0594. Structure solution and refinement based on 16400 independent reflections with $[\mathrm{I}>2 \sigma(\mathrm{I})]$ and 11301 parameters gave $R_{1}$ and $w R_{2}$ were 0.0797 and 0.2178, respectively. CCDC reference number 1490174 .

[43] I.D. Brown, D. Altermatt, Bond-valence parameters obtained from a systematic analysis of the inorganic crystal structure database, Acta Cryst. Sect. B. B41 (1985) 244-247.

[44] H.J. Pang, J. Peng, C.J. Zhang, Y.G. Li, P.P. Zhang, H.Y. Ma, Z.M. Su, A Polyoxometalate-encapsulated 3D porous metal-organic pseudo-rotaxane framework, Chem. Commun. 46 (2010) 5097-5099.

[45] H.J. Pang, C.J. Zhang, D.M. Shi, Y.G. Chen, Synthesis of a purely inorganic three-dimensional porous framework based on polyoxometalates and $4 \mathrm{~d}-4 \mathrm{f}$ heterometals, Cryst. Growth Des. 8 (2008) 4476-4480.

[46] H.Y. Zhao, J.W. Zhao, B.F. Yang, G.Y. Yang, Novel three-dimensional organic-inorganic heterometallic hybrid built by sandwich-type tetra-Mn-substituted germanotungstates through mixed $3 \mathrm{~d}$ and $4 \mathrm{f}$ metal linkers, Cryst. Growth Des. 13 (2013) 5169-5174.

[47] M.G. Liu, P.P. Zhang, J. Peng, H.X. Meng, X. Wang, M. Zhu, D.D. Wang, C.L. Meng, K. Alimaje, Organic-inorganic hybrids constructed from mixed-valence multinuclear copper complexes and templated by Keggin polyoxometalates, Cryst. Growth Des. 12 (2012) 1273-1281.

[48] M.T. Li, J.Q. Sha, X.M. Zong, J.W. Sun, P.F. Yun, L. Li, X.N. Yang, Assembly of polyoxometalate-based hybrids with different helical channels upon subtle ligand 
variation, Cryst. Growth Des. 14 (2014) 2794-2802.

[49] X.L. Wang, N. Li, A.X. Tian, J. Ying, G.C. Liu, H.Y. Lin, Two polyoxometalate-directed 3D metal-organic frameworks with multinuclear silver-ptzcycle/belts as subunits, Dalton Trans. 42 (2013) 14856-14865.

[50] I.S. Ahuja, R. Singh, L. Sriramulu, Complexes of some bivalent cobalt, nickel, copper, zinc, cadmium and monovalent silver salts with 4,4'-Bipyridyl N,N'-dioxide, Transition Met Chem. 5 (1980) 373-376.

[51] J.Q. Sha, M.T. Li, J.W. Sun, P.F. Yan, G.M. Li, L. Zhang, Two unusual 3D POM-Ag frameworks with tetragonal and dodecagonal helical channels, Chem. Asian J. 8 (2013) 2254-2261.

[52] R.J. Liu, G.J. Zhang, H.B. Cao, S.J. Zhang, Y.B. Xie, A. Haider, U. Kortz, N.S. Dalal, L.K. Yan, Enhanced proton and electron reservoir abilities of polyoxometalate grafted on graphene for high-performance hydrogen evolution, Energy Environ. Sci. 9 (2016) 1012-1023.

[53] B. Keita, L. Nadjo, Polyoxometalate-based homogeneous catalysis of electrode reactions: Recent achievements, J. Mol. Catal. A: Chem. 262 (2007) 190-215.

[54] P.P. Zhang, J. Peng, H.J. Pang, Y. Chen, M. Zhu, D.D. Wang, M.G. Liu, Y.H. Wang, A $\mathrm{Cu}$ coordination polymer-modified $\left[\mathrm{V}_{4} \mathrm{O}_{12}\right]^{4-}$ polyanion with interdigitated architecture, Inorg. Chem. Commun. 13 (2010) 1414-1417.

[55] Z.G. Han, Y.L. Zhao, J. Peng, Y.H. Feng, J.N. Yin, Q. Liu, The electrochemical behavior of Keggin polyoxometalate modified by tricyclic, aromatic entity, Electroanalysis 17 (2005) 1097-1102.

[56] P.P. Zhang, J. Peng, H.J. Pang, J.Q. Sha, M. Zhu, D.D. Wang, M.G. Liu, Z.M. Su, An interpenetrating architecture based on the Wells-Dawson polyoxometalate and $\mathrm{Ag}^{\mathrm{I}} \cdots \mathrm{Ag}^{\mathrm{I}}$ interactions, Cry. Growth Des. 11 (2011) 2736-2742.

[57] S. Berchmans, R.G. Nirmal, G. Prabaharan, S. Madhu, V.J. Yegnaraman, Templated synthesis of silver nanowires based on the layer-by-layer assembly of silver with dithiodipropionic acid molecules as spacers, Colloid. Interface Sci. 303 (2006) 604-610.

[58] J.Q. Sha, J. Peng, Y.Q. Lan, Z.M. Su, H.J. Pang, A.X. Tian, P.P. Zhang, M. Zhu, pH-Dependent assembly of hybrids based on Wells-Dawson POM/Ag chemistry, 
Inorg.Chem. 47 (2008) 5145-5153.

[59] Q. Tang, C.J. Zhang, C.H. Zhang, H.Y. Wang, Y.G. Hen, S.X. Liu, Two sandwich-type compounds from Keggin polyoxometalate, $\mathrm{d}^{10}$ metals and the product of in situ catalyzed decarboxylation of pyrazine-2, 3-dicarboxylic acid, Inorg. Chem. Commu. 15 (2012) 238-242.

[60] Y.Q. Jiao, C. Qin, H.Y. Zang, W.C. Chen, C.G. Wang, T.T. Zheng, K.Z. Shao, Z.M. Su, Assembly of organic-inorganic hybrid materials constructed from polyoxometalate and metal-1,2,4-triazole units: synthesis, structures, magnetic, electrochemical and photocatalytic properties, CrystEngComm. 17 (2015) $2176-2189$.

[61] B. Keita, A. Belhouari, L. Nadjo, R. Contant, Electrocatalysis by polyoxometalate/vbpolymer systems: reduction of nitrite and nitrite oxide, J. Electroanal. Chem. 381 (1995) 243-250.

\section{Figure captions}

Fig. 1. The coordination modes of Ag (I) ions and dpdo ligand, and view of the $2 \mathrm{D}$ bi-layer sheet.

Fig. 2. Polyhedron (a and c) and space-filling (b and d) diagrams representation of the 
3D packing arrangement based on 2D layers in which the $\mathrm{PW}_{12}$ anion as a "guest" cluster anion was encapsulated into the open channel along different directions.

Fig. 3. (a) View of the 3-D framework "host" sandwiching the Keggin ions of $\mathbf{1}$ (b) View of the arrangement of Keggin ions in the tunnels. The polyoxoanions in lay A, Olive green; in lay B, Purple.

Fig. 4. Reduction of hydrogen peroxide (a) and iodate (b) at 1-CPE in various concentrations (from inner to outer): $0,1,2,3,4 \mathrm{mM}$. The inset shows a linear dependence of the cathodic catalytic current of wave III for 1-CPE with $\mathrm{H}_{2} \mathrm{O}_{2}$ concentration (a), and $\mathrm{IO}_{3}{ }^{-}$concentration (b).

Fig. 5. Chart of the CAT vs concentration of the $\mathrm{H}_{2} \mathrm{O}_{2}$ and $\mathrm{IO}_{3}{ }^{-}$ 

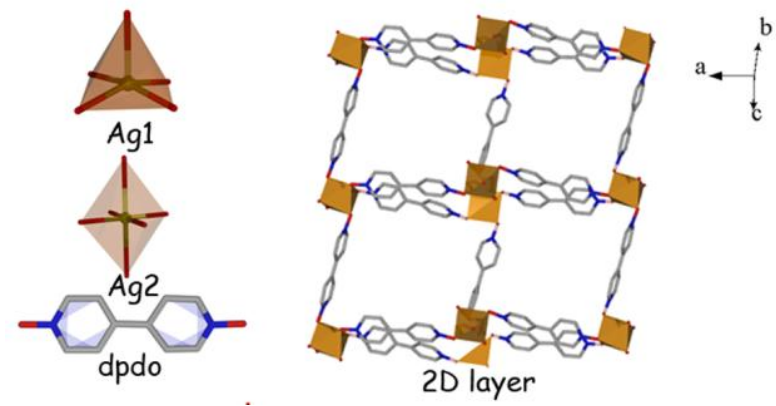

Fig. 1. The coordination modes of $\mathrm{Ag}$ (I) ions and dpdo ligand, and view of the 2D bi-layer sheet. 


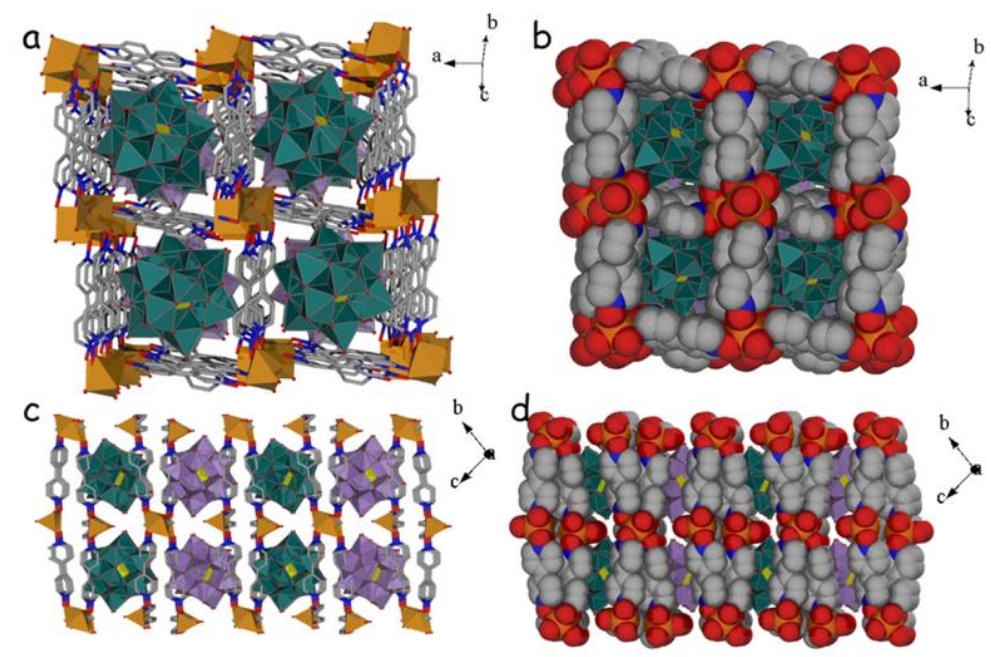

Fig. 2. Polyhedron ( $a$ and $c$ ) and space-filling ( $b$ and d) diagrams representation of the 3D packing arrangement based on $2 \mathrm{D}$ layers in which the $\mathrm{PW}_{12}$ anion as a "guest" cluster anion was encapsulated into the open channel along different directions. 


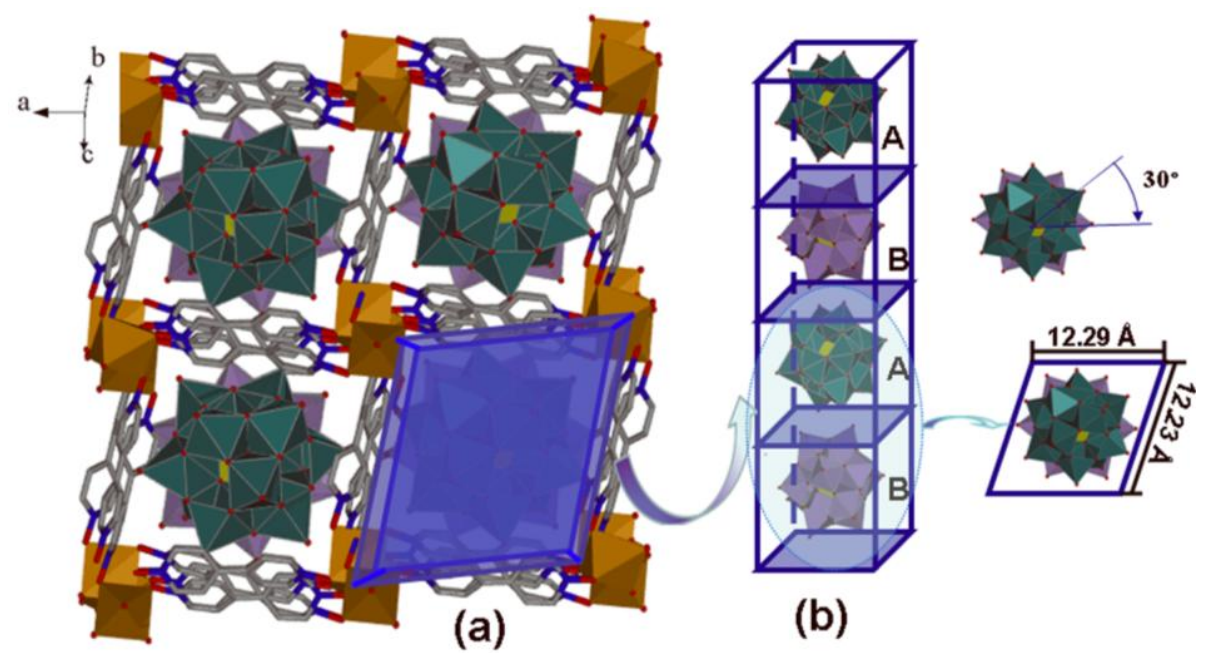

Fig. 3. (a) View of the 3-D framework "host" sandwiching the Keggin ions of 1 (b) View of the arrangement of Keggin ions in the tunnels. The polyoxoanions in lay A, Olive green; in lay B, Purple. 

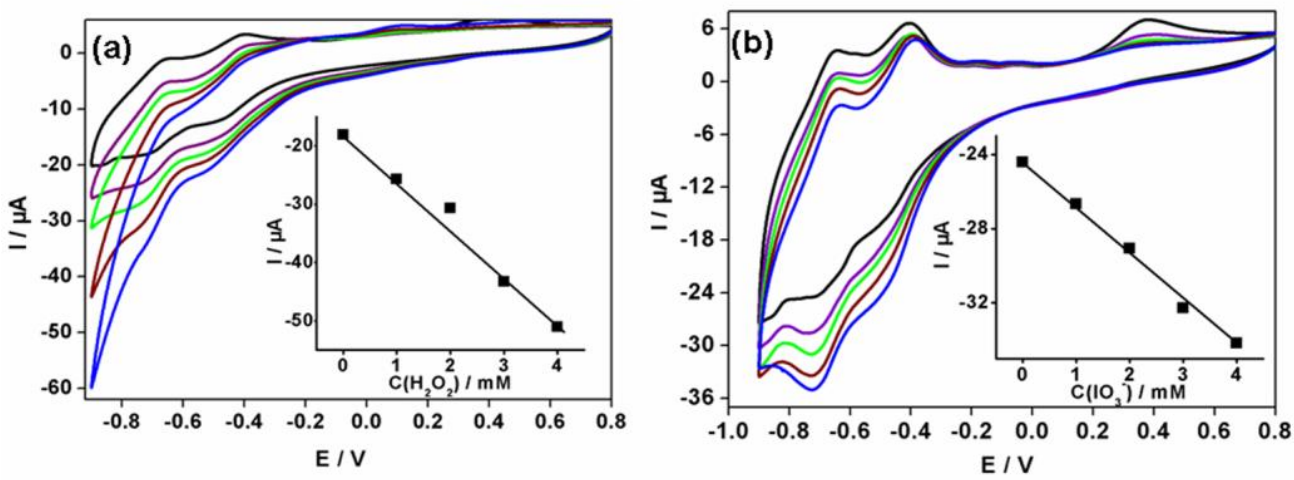

Fig. 4. Reduction of hydrogen peroxide (a) and iodate (b) at 1-CPE in various concentrations (from inner to outer): $0,1,2,3,4 \mathrm{mM}$. The inset shows a linear dependence of the cathodic catalytic current of wave III for 1-CPE with $\mathrm{H}_{2} \mathrm{O}_{2}$ concentration (a), and $\mathrm{IO}_{3}{ }^{-}$concentration (b). 
Figure 5

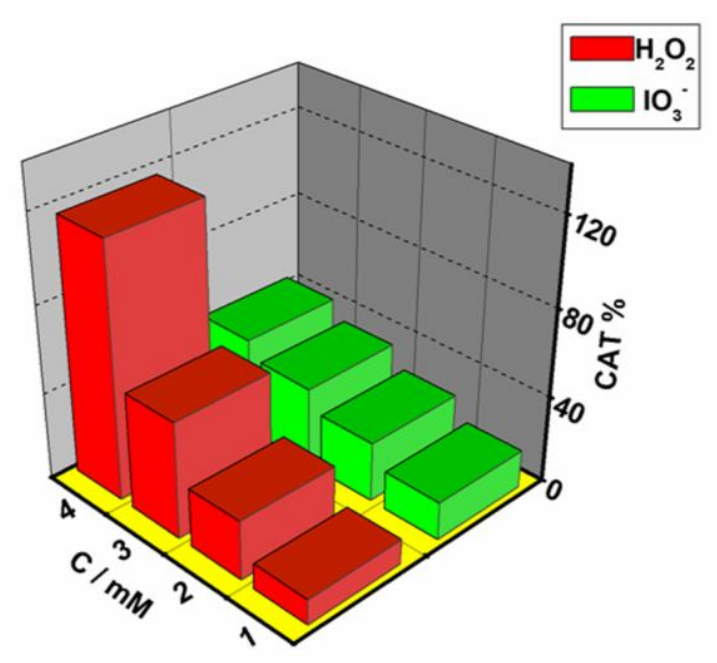

Fig. 5. Chart of the CAT vs concentration of the $\mathrm{H}_{2} \mathrm{O}_{2}$ and $\mathrm{IO}_{3}{ }^{-}$ 